\title{
Accessibility and the Bus System: Transforming the World
}

\author{
Second edition
}


Downloaded by [] on [26/04/23]. Copyright @ ICE Publishing, all rights reserved. 
Accessibility and the Bus System:

Transforming the World

\section{Second edition}

Nick Tyler 
Published by ICE Publishing, One Great George Street, Westminster, London SW1P 3AA

Full details of ICE Publishing sales representatives and distributors can be found at: www.icevirtuallibrary.com/info/printbooksales

\section{Other titles by ICE Publishing:}

Practical Road Safety Auditing, Third Edition.

M. Belcher, S. Proctor and P. Cook. ISBN 978-0-7277-6016-6

Transportation Engineering (ICE Textbook series).

J. Wright. ISBN 978-0-7277-5973-3

Highways, Fifth edition.

C. O'Flaherty with D. Hughes. ISBN 978-0-7277-5993-1

ICE Manual of Highway Design and Management.

I. Walsh (ed.). ISBN 978-0-7277-4111-0

www.icevirtuallibrary.com

A catalogue record for this book is available from the British Library.

ISBN 978-0-7277-5980-1

(c) Thomas Telford Limited 2016

ICE Publishing is a division of Thomas Telford Ltd, a wholly-owned subsidiary of the Institution of Civil Engineers (ICE).

All rights, including translation, reserved. Except as permitted by the Copyright, Designs and Patents Act 1988, no part of this publication may be reproduced, stored in a retrieval system or transmitted in any form or by any means, electronic, mechanical, photocopying or otherwise, without the prior written permission of the publisher, ICE Publishing, One Great George Street, Westminster, London SW1P 3AA.

This book is published on the understanding that the author is solely responsible for the statements made and opinions expressed in it and that its publication does not necessarily imply that such statements and/or opinions are or reflect the views or opinions of the publishers. Whilst every effort has been made to ensure that the statements made and the opinions expressed in this publication provide a safe and accurate guide, no liability or responsibility can be accepted in this respect by the author or publishers.

Whilst every reasonable effort has been undertaken by the authors and the publisher to acknowledge copyright on material reproduced, if there has been an oversight please contact the publisher and we will endeavour to correct this upon a reprint.

Commissioning Editor: Amber Thomas

Development Editor: Maria Inês Pinheiro

Production Editor: Abigail Neale

Market Development Executive: Elizabeth Hobson

Typeset by Academic + Technical, Bristol

Index created by Nigel D'Auvergne

Printed and bound by TJ International Ltd, Padstow 
Part 1: Philosophy - Why?

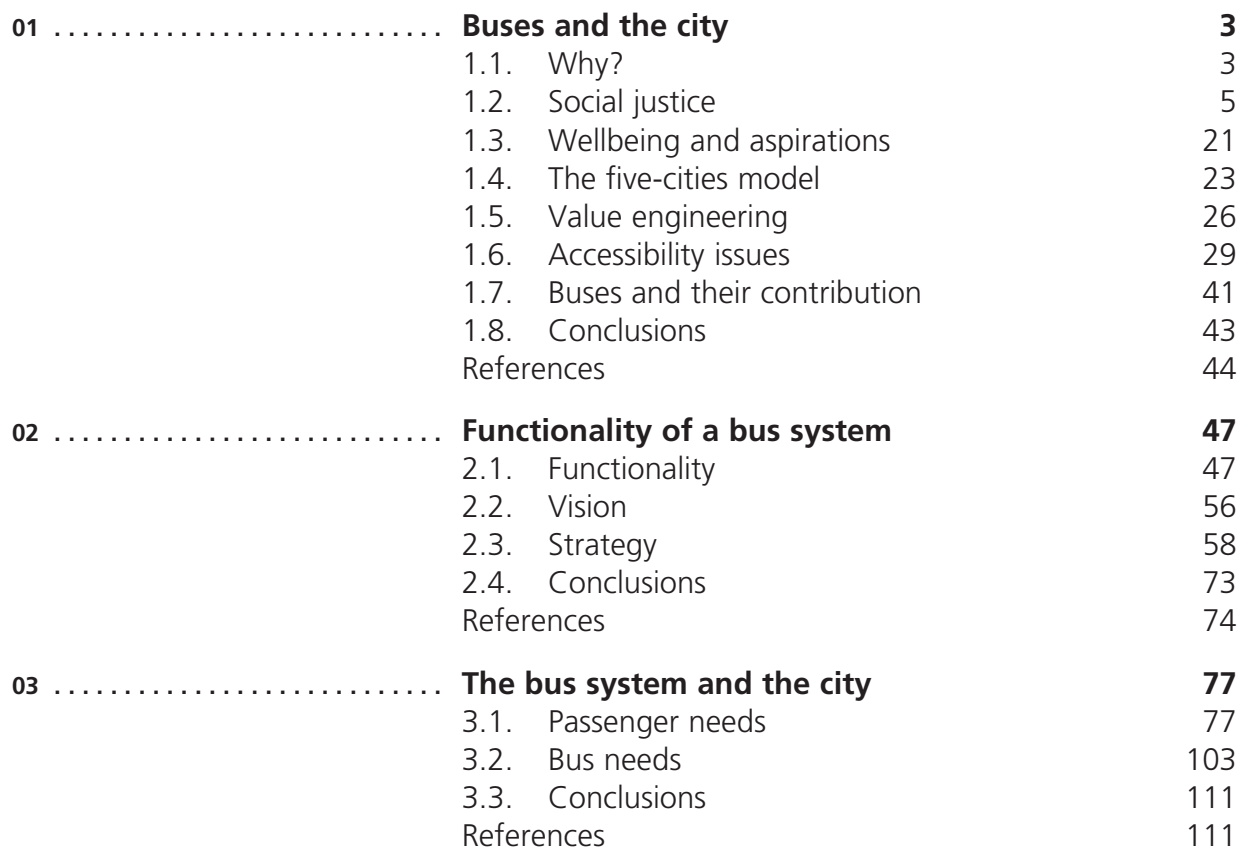

\section{Part 2: Science - What?}

04

\section{Reaching the bus}

4.1. General considerations

4.2. Pedestrians

4.3. At the bus stop

4.4. Boarding/alighting the buses

4.5. Interfaces at the bus stop

4.6. People-centred approach to definition of bus stop design

4.7. Conclusions References

Design of accessible bus stops: Transforming the world

5.1. Design in the decision-making process

5.2. Aesthetics

5.3. Operations
115

115

115

136

158

165

187

204

205 
5.4. Information and communication along the journey chain

5.5. Putting it all together 273

5.6. Conclusions 276

References $\quad 277$

$06 \ldots \ldots \ldots \ldots \ldots$ Travelling in the bus 279

6.1. Introduction 279

6.2. The bus and the five cities 279

6.3. The bus as a vehicle 307

6.4. Conclusion 318

References 318

$07 \ldots \ldots \ldots \ldots \ldots \ldots \ldots$ Public participation in bus system design $\quad 319$

7.1. Introduction 319

7.2 Participating with the public 326

7.3 Public participation - the people 328

7.4 Public participation - the how (and what) 331

7.5 The roadmap in Lima 336

7.6. Discussion 337

7.7. Conclusions 340

References $\quad 342$

Part 3: Examples - Where?

$08 \ldots \ldots \ldots \ldots \ldots \ldots \ldots \ldots \ldots$ Examples

345

8.1. Medellín 345

8.2. London 348

8.3. Asheville, North Carolina 351

8.4. Lima 355

8.5. Conclusions 359

References 360

Part 4: Ingenuity - How?

$09 \ldots \ldots \ldots \ldots \ldots \ldots \ldots \ldots$ Opportunities

9.1. Can the bus system work for us? 365

9.2. The role of the vision 366

9.3. Structuring the decisions 366

9.4. Systems and value 368

9.5. Buses and the city 369

9.6. Implementing a transformation 371

9.7. Grasping the opportunity 376

Reference 381

$10 \ldots \ldots \ldots \ldots \ldots \ldots \ldots \ldots$ Conclusions 383

10.1. General points 383

10.2. Transforming the world 386

Index 389 


\section{About the author}

Nick Tyler CBE, MSc, PhD, ARCM, FICE, FREng, FRSA is the Chadwick Professor of Civil Engineering at University College London, where he teaches and researches the ways in which people interact with their immediate environments. He set up the Accessibility Research Group within the Centre for Transport Studies, with a team of researchers investigating many aspects of accessibility and public transport, including the Pamela pedestrian environment laboratory, which is being used to develop models for accessible pedestrian infrastructure.

Nick is also the Director of the UCL CRUCIBLE Centre, which is a centre for interdisciplinary research on lifelong health and wellbeing, and a Co-Director of UCL as urban design research studio.

He is a Fellow of the Institution of Civil Engineers and a Fellow of the Royal Society of Arts. He was appointed a CBE in the New Year's Honours 2011 for services to technology and elected Fellow of the Royal Academy of Engineering in 2014. 
Downloaded by [] on [26/04/23]. Copyright @ ICE Publishing, all rights reserved. 
Transforming the world is a big task, so one should not embark on it alone. The intention of this book is to be a companion, to start a conversation about what people need from their cities and bus systems that provide the means to reachtheir desired activities, and how we can stimulate and make the changes that will indeed transform the world. The idea is that the conversation should take unexpected turns, start from unusual places and lead to new ways of thinking, not only about the bus system, but about the world. However, what have buses to do with transforming the world? Buses and the bus system are often disregarded, unseen or ignored, but they enable people to reach - or miss - their life-changing events. A city cannot function without some sort of publicly accessible transport system and the default way of providing this is the bus system.

Crucial, yet ignored, buses form part of the essence of the city. The French impressionist composer Claude Debussy said about the nuances of music: 'La musique est le silence entre les notes' ('the music is the silence between the notes'), that without the almost imperceptible silences between the notes, the notes would just be meaningless sounds. The same is true of a city: a city is people and its essence is the unobserved link between their activities without those links the activities are just meaningless points in a calendar, buildings are just buildings, not the 'loci of foci' made by people coming together to create something better, and the people just live their lives without the benefit of being in a society. These links are created in an ever-changing world of interactions between people and their immediate environment: the way these combine into that essence of the city is provided by the bus system.

Yet people often do not see it this way. They see buses as negative, polluting, obstructions, messy, dirty, inefficient ... Why do they not see the bus system for the positive contribution to their lives that it is? My case is that the reason for this misperception is the way the bus system is conceived and designed. It is conceived as a way of doing the minimum, making money, creating employment by moving people, and is designed to do this at the lowest possible cost. The aims of the system are often not designed to improve society or the quality of life but simply to carry as many people as possible (and to do the same the next day). My hope is that this book will, in the manner of a companion, help to focus the mind on the positives, what the bus system could do if we were to 
think more of it, give it higher aims, and treat it with the respect, value and investment it deserves. The bus system should be one of the glories of a city - let's make it so!

The ubiquity and variety of buses and bus systems around the world means that they can be a real force for change. Instead of thinking of them as expensive but necessary problems that need to be tolerated, we can think of them as forces for good, with the capability of improving quality of life and wellbeing in society through the way they are designed and operated. My intention in writing this book is to show ways of thinking about the bus system that help to change perceptions and to make it possible for the bus system to transform the world and to make it a better place for everyone. Alternatively, for those people who wish to transform a city in terms of the way in which people relate, both to each other and to the city itself, the book should capture their minds and show them things that they could do - if only they could just stop thinking about the bus system in the same old way.

Just as a companion can be quite a challenging person, this book is structured in a number of different ways. The thought processes behind the bus system (what it is trying to do, how it relates to a city and, more importantly, its people) come at the beginning - the 'why'. Then I move on to what a bus system might need to be to meet these aims - the 'what'. Then I consider some approaches to achieve this, including the science (knowledge and thinking behind the processes) - the 'how'. However, it is important to recognise that sometimes the reason for things being done in an inappropriate way is not the design or the thinking per se, but the way people make the decisions that need to be made. So the decision-making process also comes under scrutiny.

The book does not contain all of the answers; just like a companion, it is there to ask the questions and lead you towards creating the answers yourself, through explanations, illustrations, analogies and examples, because transforming the world starts with transforming ourselves. 
The ideas expressed in this book are mine, but they can only arise because of the inspiration that I receive from the people with whom I have the pleasure to work, think and create. It is hard - and wrong - to single out anyone in particular. It is the result of a genuine mixing of open minds and sharing of different expertise. I am really fortunate to have such people around to keep me in line, inspire and encourage me to look at things in an open, innovative and 'no baggage' kind of way.

Nevertheless, I would like to acknowledge some people who have been particularly inspirational in different ways in the course of writing this book: Sara Adhitya, David Ashmore, Simon Buxton, Martha Caiafa, Tsu-Jui Cheng, Anna Clark, Brian Collins, Emily Digges la Touche, Taku Fujiyama, Catherine Holloway, Peter Jones, Xenia Karekla, Makoto Okada, Adriana Ortegon, Liliana Ortega, Nikos Papadosifos, David Price, Claudia Ramírez, Kristy Revell, Ian Scott, Paulo Silva, Roselle Thoreau, Pam Turpin, Tianyu Wang, Nigel Wilson and Jo Wolff - any one of whom could have written parts of the book. I take the blame for mixing their ideas and putting them together, possibly in ways they had not envisaged, and presenting the resulting blend in the book as a whole. Each one of these people (and many more) has helped by chipping and polishing the rough pebble of an idea towards making it a multifaceted diamond. I hope the resulting book does all their insights and help the justice they deserve. I am indebted to Janette Yacoub, who helped me put my ramblings into some order so that the manuscript would be intelligible to the publisher. Of course, I have a huge debt of gratitude to my wife, Katrina, and Quincy, who together kept me in one piece during the whole process. 
Downloaded by [] on [26/04/23]. Copyright @ ICE Publishing, all rights reserved. 


\section{Introduction}

The bus is one of the most common artefacts of city life, almost unseen because of its ubiquity in cities all over the world. It is impossible to know exactly how many there are in the world, but most cities of any size have several thousand. Yet, as a system, the bus system is barely understood - by the passengers who use them, the public in general, the industry or its regulators. This book seeks to change this situation so that people can use the bus system to improve their quality of life so that they can live, work and play in cities around the world.

The key concept here - and the rationale for the title of his book - is that the bus system does not exist for those people who are not able to access it, so it is essential that we make the bus system accessible. What we mean by 'accessibility', its importance and the influence it has on quality of life is discussed in Part 1 of the book. The first edition of this book sought to show the outcomes of research that help to improve the accessibility of the bus system. Many of those concepts still stand and research in the intervening 10 years or so has refined and improved on these and introduced more. This technical side of the process is set out in Part 2. Some examples of bus systems around the world are analysed in Part 3 to show what has been done in bus systems to change the travel opportunities in cities around the world. Part 4 brings these three strands together to develop a strategy for using the bus system as an integral part of improving people's lives in cities around the world.

\section{A word about engineering ...}

The word 'engineering' is used a lot in this book. However, I have a particular way of looking at 'engineering' and it is important to understand this in order to understand the core message of the book. 'Engineering' comes from a Latin word 'ingeniare' meaning 'to contrive or to devise'. It is not too difficult to see that other modern English words stem from the same root - such as 'ingenious' or 'ingenuity'. It is reasonable to say that, to the modern English ear, the word 'engineer' suggests the person who makes an engine work (in US English, it is the person who drives a train) and that the more ephemeral implication of being ingenious - devising ways of making things happen - is a little lost.

Vitruvius wrote the first books about buildings, in which he set out three principles: buildings should be simple, useful and beautiful. This is an excellent ambition for 
engineers. The first person of record to hold the title of 'Engineer' was Leonardo da Vinci, arguably one of the world's most ingenious people. He was clearly in line with Vitruvius (he even drew the 'Vitruvian Man', which shows that how to achieve the Vitruvian ideal it is necessary to encompass both the technical and sociopolitical worlds). When you read the words 'engineer' and 'engineering' in this book, you should interpret them in the da Vinci way - visionary, curious, innovative, unafraid to challenge received knowledge, unabashed at trying new things, looking at the world in a new way in order to reach a new outcome for a new world - and with his illustration of the Vitruvian ideal in mind. This does not only apply to hardware (such as engines) but to whole systems, ideas, concepts, society ... to think that the humble bus can transform the world ... 